\title{
Association of clinical features with HLA in chronic pulmonary thromboembolism
}

\author{
N. Tanabe*, A. Kimura", , S. Amano*, O. Okada*, Y. Kasahara*, K. Tatsumi*, \\ M. Takahashi ${ }^{\#}$, H. Shibata ${ }^{\#}$, M. Yasunami" and T. Kuriyama*
}

ABSTRACT: The aetiology of chronic thromboembolic pulmonary hypertension (CTEPH) is largely unknown and may be heterogeneous, because there are several ethnic differences in the clinical characteristics of CTEPH. Female predominance and a higher ratio of chronic to acute pulmonary thromboembolism have been reported in Japan as compared with the USA. Because such ethnic differences may be controlled by genetic factors, the current study investigated HLA polymorphisms in Japanese patients with CTEPH.

HLA typing by serological and/or DNA typing methods was performed (for HLA-A, B, DPB1, DRB1) in 80 patients and 678 controls, and the association of clinical characteristics with HLA alleles was studied.

The frequencies of HLA-B*5201 (40 versus $24 \%$ ) and DPB1*0202 (19 versus $6 \%$ ) were significantly higher in the patients. HLA-B*5201 positive patients showed a significant female predominance. Total pulmonary vascular resistance and mixed venous oxygen tension were better in the HLA-B*5201 positive patients. In contrast, cardiac index and gas exchange parameters were worse in the HLA-DPB1*0202 positive patients. In the patients carrying HLA$B * 5201$ and/or -DPB1*0202, the frequency of deep vein thrombosis was significantly lower than the other patients.

These observations suggested that both the susceptibility and clinical characteristics of chronic thromboembolic pulmonary hypertension were controlled in part by the HLA-B and -DPB1 loci.

KEYWORDS: HLA, polymorphism, pulmonary embolism, pulmonary hypertension, thromboembolic disease

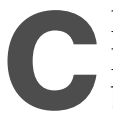

hronic thromboembolic pulmonary hypertension (CTEPH) is characterised by pulmonary hypertension caused by single or recurrent pulmonary emboli presumably arising from sites of venous thrombosis [1, $2]$. The incidence of deep vein thrombosis in CTEPH, however, is $12-38 \%$ in Japan [3-5] and $35-45 \%$ in the USA [2]. The reason why the patients cannot resolve the emboli is largely unknown, but several factors, such as the volume of embolic material and abnormal mechanism of thrombolysis, may be involved [2]. In addition, there are some differences in clinical characteristics between Japanese patients and Caucasian patients in the USA. The female-to-male ratio in the patients is 2.1 in Japan [3], much higher than that of 0.7 in the USA [6]. The ratio of the incidence of chronic to acute pulmonary thromboembolism is 0.22 in Japan [3], again much higher than that of 0.001-0.005 in the USA [1, 2]. These data indicate the ethnic differences in clinical characteristics of CTEPH, suggesting that some genetic factors might be involved in the aetiology or pathogenesis.
Because the HLA system is highly polymorphic, allelic distribution is different in each ethnic group, and clinical characteristics of autoimmune diseases are differently associated with HLA alleles [7-10], it was speculated that the genetic factors controlling the different clinical characteristics and/or susceptibility to CTEPH might in fact be the HLA system. Only a few reports were concerned with the associations of serologically determined HLA with primary pulmonary hypertension; HLA-DR3, DR52, and DQ2 [11], DR6 and DR52 [12], and DQ7 [13] showed marginal associations in particular conditions in Caucasoid populations. This study investigated the association of HLA with CTEPH at the DNA level and analysed the relevance of HLA alleles in controlling the clinical characteristics in a Japanese population.

\section{MATERIAL AND METHODS}

\section{Subjects and study design}

Blood samples were obtained from 80 Japanese patients with CTEPH diagnosed at Chiba University Hospital, Chiba, Japan. CTEPH was defined as mean pulmonary arterial pressure

\section{AFFILIATIONS}

*Dept of Respirology, Graduate School of Medicine, Chiba University, Chiba,

\#Dept of Molecular Pathogenesis, Medical Research Institute, and 'Laboratory of Genome Diversity, School of Biomedical Science, Tokyo Medical and Dental University, Tokyo, Japan.

\section{CORRESPONDENCE}

N. Tanabe

Dept of Respirology

Graduate School of Medicine

Chiba University

1-8-1 Inohana Chuou-ku

Chiba 260-8670

Japan

Fax: 81432262176

E-mail: ntanabe@faculty.chiba-u.jp

Received:

April 122004

Accepted after revision

September 212004 
$(P$ pa $) \geqslant 25 \mathrm{mmHg}$ with normal wedge pressure in patients who had symptoms for $>6$ months $[4,14]$. Chronic thromboembolic findings were confirmed by pulmonary angiography [15]. All patients were examined for deep vein thrombosis by contrast venography or venous ultrasonography. Altogether, 39 patients underwent pulmonary thromboendarterectomy. Control subjects were healthy Japanese selected at random (age at blood sampling $43.3 \pm 10.9$ yrs, \% male=69.3).

Frequencies of HLA alleles in the patients were compared with those in the controls. Clinical characteristics were compared between the subgroups with or without the disease-associated HLA alleles. All subjects gave their informed consent. The study protocol was approved by the Research Ethics Committee of Chiba University School of Medicine and the Ethics Reviewing Committee of Medical Research Institute, Tokyo Medical and Dental University.

\section{Measurements}

Pulmonary haemodynamics, cardiac output by thermodilution technique, and blood gases were measured in the supine position while breathing air. Cardiac index and total pulmonary vascular resistance (ratio of mean $P$ pa to cardiac output) were calculated. The time interval from onset of symptoms to catheterisation, and the Fletcher-Hugh-Jones classification for severity of dyspnoea [16] were evaluated.

\section{HLA typing}

Serological HLA typing of A and B antigens was done by standard microcytotoxicity test [17]. Genomic DNA was obtained from peripheral blood leukocytes by QIAamp DNA blood minikit (Qiagen, Hilden, Germany). DNA typing of HLA-A, -B, -DRB1, and -DPB1 genes was performed by using RELI-typing kit (Dynal, Oslo, Norway) and/or using SSO probes as previously reported $[18,19]$.

\section{Stratification of patients by the location of thrombi}

The patients were divided into two subgroups, central predominant type and peripheral predominant type, according to the location of thrombi by angiographies and spiral computed tomography angiographies. The central predominant type $(n=58)$ was defined by thrombi of lobar arteries or proximal thrombi location, while the peripheral predominant type $(n=22)$ was defined by thrombi in segmental arteries or distal location [20].

\section{Statistical analysis}

Frequencies of HLA alleles in the patients were compared with those in the controls. Odds ratio (OR) was calculated to estimate the strength of association from a $2 \times 2$ table, and statistical significance was calculated by Chi-squared test. When the number of patients in each column of the $2 \times 2$ table was $<5$, Fisher's exact probability test was used. Bonferroni correction was used to reduce type 1 errors because all of the alleles in the patients were compared with those in the controls. Corrected $\mathrm{p}(\mathrm{Pc})$ value was calculated by multiplying the $\mathrm{p}$-value by the number of alleles found in the Japanese controls; HLA-A $(n=9)$, HLA-B $(n=23)$, HLA-DPB1 $(n=15)$, and HLA-DRB1 $(n=26)$. To determine the independence of a disease-associated HLA allele from another associated HLA allele, both patients and controls were divided into two groups according to the presence of the HLA alleles, and OR was calculated as described previously [8, 21]. Clinical characteristics were compared between the subgroups with or without the disease-associated HLA alleles by Mann-Whitney U-test or Chi-squared test. A p-value (or Pc value) of $<0.05$ was considered significant.

\section{RESULTS}

\section{Patient characteristics}

Patient characteristics are shown in table 1 . There were more female patients $(n=61)$ than male patients $(n=19)$. Interval from the onset of symptom to catheterisation was $29 \pm 28$ months. Age at catheterisation varied from 18-77 yrs, with a mean \pm SD of $53 \pm 12$. Altogether, 21 patients $(26.3 \%)$ had a history of deep vein thrombosis, $18(22.5 \%)$ revealed abnormalities in the screening for coagulopathy, 12 (15\%) had lupus anticoagulant and/or antiphospholipid antibodies [22, 23] and $10(12.5 \%)$ had a history of other thrombosis. No patients had cardiac shunt diseases. One patient had splenectomy for haemolytic anaemia, but none had inflammatory bowel diseases. Mean $P$ pa, cardiac index and total pulmonary vascular resistance

\section{TABLE 1 Clinical characteristics of patients}

\begin{tabular}{|c|c|}
\hline Age yrs & $53 \pm 12$ \\
\hline Female versus male & $61: 19$ \\
\hline $\begin{array}{l}\text { Central versus peripheral } \\
\text { predominant type }\end{array}$ & $58: 22$ \\
\hline Duration of symptoms months & $29 \pm 28$ \\
\hline \multicolumn{2}{|l|}{ Underlying disease } \\
\hline Deep vein thrombosis & $21(26.3)$ \\
\hline Coagulopathy & $18(22.5)$ \\
\hline $\begin{array}{l}\text { Lupus anticoagulant and/or } \\
\text { antiphospholipid antibodies }\end{array}$ & $12(15)$ \\
\hline Antithrombin III deficiency & 3 \\
\hline Thrombocytosis & 2 \\
\hline Protein S deficiency & 1 \\
\hline Other thrombosis & $10(12.5)$ \\
\hline Stroke & 5 \\
\hline Transient ischemic attack & $2^{\#}$ \\
\hline Ischemic heart disease & 4 \\
\hline Malignancy & 2 \\
\hline Mean Ppa mmHg & $42.9 \pm 10.3$ \\
\hline Cardiac index $\mathrm{L} \cdot \mathrm{min} \cdot \mathrm{m}^{-2}$ & $2.64 \pm 0.54$ \\
\hline $\begin{array}{l}\text { Total pulmonary vascular } \\
\text { resistance dynes } \cdot \mathbf{s} \cdot \mathrm{cm}^{-5}\end{array}$ & $876 \pm 303$ \\
\hline $\mathrm{Pa}, \mathrm{O}_{2} \mathrm{kPa}$ & $8.0 \pm 1.4$ \\
\hline $\mathrm{PAa}, \mathrm{O}_{2} \mathrm{kPa}$ & $6.0 \pm 1.5$ \\
\hline $\mathrm{Pv}, \mathrm{O}_{2} \mathrm{kPa}$ & $4.5 \pm 0.8$ \\
\hline \multicolumn{2}{|l|}{$\begin{array}{l}\text { Fletcher-Hugh-Jones } \\
\text { classification }\end{array}$} \\
\hline II & $24(30)$ \\
\hline III & $31(39)$ \\
\hline IV & 3 \\
\hline V & 2 \\
\hline
\end{tabular}

Values are presented as mean $\pm \mathrm{SD}$ or $\mathrm{n}(\%)$. Duration of symptoms: duration from symptoms onset to cardiac catheterisation. Ppa: pulmonary arterial pressure; $\mathrm{Pa}, \mathrm{O}_{2}$ : arterial oxygen tension; $\mathrm{PAa}, \mathrm{O}_{2}$ : alveolar-arterial oxygen tension difference; $P \mathrm{P}_{1} \mathrm{O}_{2}$ : mixed venous oxygen tension. ${ }^{\#}$ : one patient with transient ischemic attack also had Ischemic heart disease. $n=80$. 


\begin{tabular}{lcccll} 
TABLE 2 & $\begin{array}{l}\text { Association of HLA with chronic thromboembolic } \\
\text { pulmonary hypertension }\end{array}$ \\
& Patients & Controls & Odds ratio & p-value & pc $^{\#}$ \\
\hline Subjects n & 80 & 678 & & & \\
B*5201 & $32(40)$ & $161(24)$ & 2.14 & 0.0016 & 0.037 \\
DPB1*0202 & $15(19)$ & $43(6)$ & 3.41 & 0.00008 & 0.0014 \\
DPB1*0901 & $25(31)$ & $138(20)$ & 1.98 & 0.025 & 0.44 \\
DRB1*1301 & $4(5)$ & $8(1)$ & 4.41 & 0.029 & 0.75 \\
DRB1* $\mathbf{1 5 0 2}$ & $31(39)$ & $156(23)$ & 2.12 & 0.002 & 0.05 \\
\hline
\end{tabular}

Data presented as $n(\%)$ unless otherwise stated. HLA-A $(n=9)$, HLA-B $(n=23)$, HLA-DPB1 $(n=15)$, HLA-DRB1 $(n=26)$. \#: corrected $p$-value obtained by multiplying the $\mathrm{p}$-value by the number of alleles found in the Japanese controls.

were $42.9 \pm 10.3 \mathrm{mmHg}, 2.64 \pm 0.54 \mathrm{~L} \cdot \mathrm{min}^{-1} \cdot \mathrm{m}^{-2}$, and $876 \pm 303$ dynes $\cdot \mathrm{s} \cdot \mathrm{cm}^{-5}$, respectively. Arterial oxygen tension $\left(\mathrm{Pa}, \mathrm{O}_{2}\right)$, alveolar-arterial oxygen tension difference $\left(P(\mathrm{~A}-\mathrm{a}), \mathrm{O}_{2}\right)$, and mixed venous oxygen tension $\left(P_{\overline{\mathrm{v}}}, \mathrm{O}_{2}\right)$ were $8.0 \pm 1.4,6.0 \pm 1.5$, and $4.5 \pm 0.8 \mathrm{kPa}$, respectively. Twenty-four $(30.0 \%)$ patients were classified as Fletcher-Hugh-Jones grade 2, and the remaining 56 patients were greater than or equal to grade 3 . The patients were also classified as New York Heart Association functional class II $(n=29)$, III $(n=46)$, and IV $(n=5)$.

\section{Frequencies of HLA alleles}

Table 2 summarises the results of HLA analysis. Only the alleles showing significant associations with CTEPH are shown. The frequency of HLA-B 5201 in the patients was significantly higher than in the controls (40 versus $24 \%$, OR 2.14, $\mathrm{p}=0.0016, \mathrm{pc}=0.037,95 \%$ confidence interval $(95 \% \mathrm{CI})$ 1.29-3.55). As for the class II alleles, significant positive association was observed with HLA-DPB1*0202 (19 versus $6 \%, \mathrm{OR}=3.41, \mathrm{p}=0.00008, \mathrm{pc}=0.0014,95 \% \mathrm{CI} 1.71-6.74)$. The frequencies of HLA-DPB1*0901 (31 versus 20\%, OR 1.78, $\mathrm{p}=0.025, \mathrm{pc}=0.44,95 \%$ CI $1.04-1.54)$ and HLA-DRB1*1502 (39 versus 23\%, OR 2.12, $\mathrm{p}=0.002, \mathrm{pc}=0.05,95 \%$ CI 1.27-3.53), both in linkage disequilibrium with HLA-B $* 5201$ in Japanese $[7,8]$, were also significantly higher in the patients. The frequency of HLA-DRB1*1301 in the patients was also higher, but as the number of patients was small, the association was not significant after the p-value was corrected.

To examine the independent associations of HLA-B*5201, -DRB1*1502, -DPB1*0901, and -DPB1*0202 alleles with CTEPH,

\begin{tabular}{|c|c|c|c|c|}
\hline TABLE 3 & \multicolumn{4}{|c|}{$\begin{array}{l}\text { Independence of HLA alleles in association with } \\
\text { chronic thromboembolic pulmonary hypertension }\end{array}$} \\
\hline HLA-B*5201 & Patients & Controls & Odds ratio & p-value \\
\hline \multicolumn{5}{|l|}{ Positives } \\
\hline Subjects n & 32 & 161 & & \\
\hline DRB1*1502 & $30(94)$ & $144(89)$ & 1.77 & 0.45 \\
\hline DPB1*0901 & $24(75)$ & $119(74)$ & 1.16 & 0.90 \\
\hline DPB1*0202 & $4(13)$ & $3(2)$ & 7.52 & 0.0033 \\
\hline \multicolumn{5}{|l|}{ Negatives } \\
\hline Subjects n & 48 & 517 & & \\
\hline DRB1*1502 & $1(2)$ & $12(2)$ & 0.90 & 0.92 \\
\hline DPB1*0901 & $1(2)$ & $19(4)$ & 0.56 & 0.57 \\
\hline DPB $1 * 0202$ & $11(23)$ & $40(8)$ & 3.55 & 0.00045 \\
\hline
\end{tabular}

Data are presented as $n(\%)$ unless otherwise stated.

both the patients and controls were divided into two groups, HLA-B $* 5201$ positive and HLA-B $* 5201$ negative, and compared for the frequencies of disease-associated HLA alleles. As shown in table 3 , the frequency of HLA-DPB1*0202 was significantly greater in both the HLA-B*5201 positive and negative groups. In clear contrast, the frequencies of HLADRB1*1502 and -DPB1*0901 did not show a significant difference between the patients and controls in the $B^{* 5201-p o s i t i v e ~ a n d ~}$ -negative groups. In the HLA-B*5201-negative group the ORs of DRB1*1502 (0.90) and DPB1*0901 (0.56) were $<1$.

Although not shown in the tables, between the patients and controls the OR of HLA-B*5201 in the DRB1*1502-positive group was 2.50 , and that in the DRB1*1502-negative group was 1.26 , while the OR of HLA-B*5201 in the DPB1*0901-positive group was 3.83, and that in the DPB1*0901-negative group was 2.02 .

\section{Association of HLA and clinical characteristics}

As shown in table 4, the frequencies of HLA-B*5201 and -DPB1*0202 were higher in CTEPH, especially in the patients with central predominant type (HLA-B ${ }^{*} 5201$ : 46\%, OR 2.75, $p=0.00034,95 \%$ CI 1.49-5.06; HLA-DPB1*0202: 21\%, OR 3.96, $\mathrm{p}=0.000084,95 \%$ CI 1.78-8.68). Although the number was small, the frequency of HLA-B*5201 in the patients with peripheral predominant type did not differ from that in the controls, while that of HLA-DPB $1 * 0202$ was a little, but not

TABLE 4 Frequencies of HLA alleles in the patients stratified by location of thrombi

\begin{tabular}{|c|c|c|c|c|c|c|c|}
\hline & \multirow{2}{*}{$\begin{array}{c}\text { Central } \\
\text { predominant } \\
\text { type }\end{array}$} & \multirow{2}{*}{$\begin{array}{l}\text { Peripheral } \\
\text { predominant } \\
\text { type }\end{array}$} & \multirow[t]{2}{*}{ Controls } & \multicolumn{2}{|c|}{$\begin{array}{l}\text { Central predominant type versus } \\
\text { controls }\end{array}$} & \multicolumn{2}{|c|}{$\begin{array}{l}\text { Peripheral predominant type versus } \\
\text { controls }\end{array}$} \\
\hline & & & & Odds ratio & $p$-value & Odds ratio & p-value \\
\hline Subjects $n$ & 52 & 28 & 678 & & & & \\
\hline$B * 5201$ & $24(46)$ & $8(29)$ & $161(24)$ & 2.75 & 0.00034 & 1.28 & 0.56 \\
\hline DPB1*0202 & $11(21)$ & $4(14)$ & $43(6)$ & 3.96 & 0.000084 & 2.46 & 0.10 \\
\hline
\end{tabular}

Data are presented as $n(\%)$ unless otherwise stated 


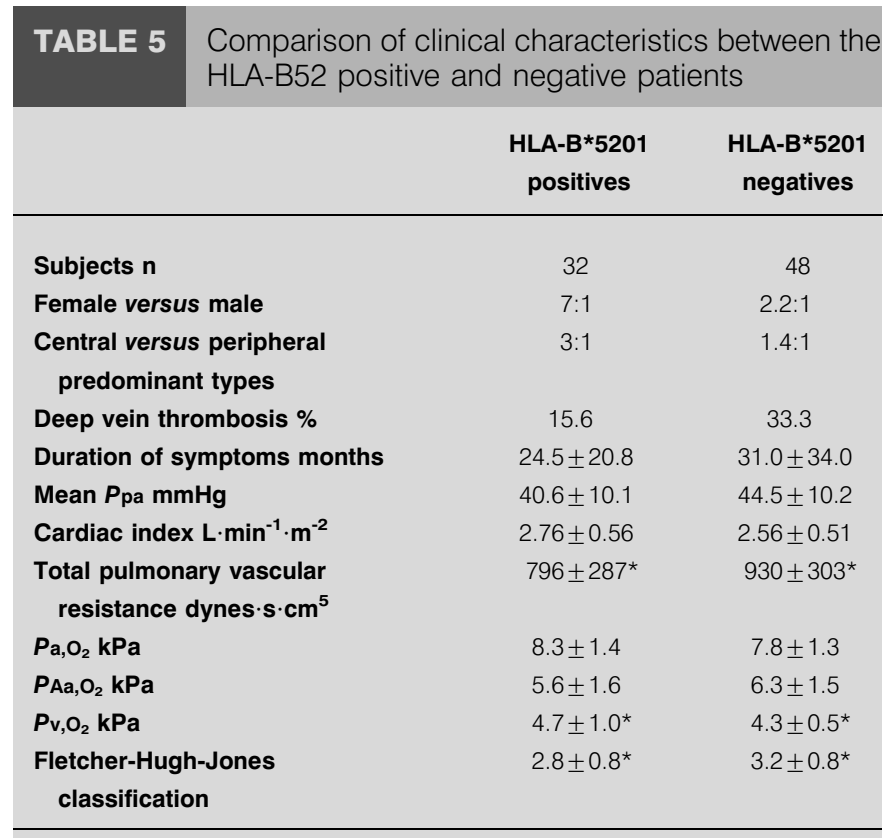

Values are presented as mean $\pm S D$ unless otherwise stated. Duration of symptoms: duration from symptoms onset to cardiac catheterisation. Ppa: pulmonary arterial pressure; $\mathrm{Pa}_{2} \mathrm{O}_{2}$ : arterial oxygen tension; $\mathrm{PAa}_{\mathrm{A}_{2}}$ : alveolararterial oxygen tension difference; $P \mathrm{v}_{1} \mathrm{O}_{2}$ : mixed venous oxygen tension. *: $\mathrm{p}<0.05$, Mann-Whitney U-test and Chi-squared test. significantly, more frequent $(14 \%$, OR $2.46, p=0.10,95 \% \mathrm{CI}$ 0.69-7.93) in comparison with the control group.

Clinical characteristics were compared between the HLA$B * 5201$ positive and negative patients as shown in table 5 . The female-to-male ratio was 7.0 in the HLA-B*5201 positives, much higher than 2.2 in the HLA-B*5201 negatives. The frequency of HLA-B $* 5201$ was $45.9 \%$ in the female patients and $21.0 \%$ in the male patients $(p=0.05, O R 3.18)$. The incidence of deep vein thrombosis in the HLA-B*5201 positives was lower than that in the HLA-B*5201 negatives, although it did not reach statistical significance $(p=0.08)$. Total pulmonary vascular resistance, $P_{\mathrm{v}}, \mathrm{O}_{2}$, and the Fletcher-Hugh-Jones classification were significantly better in the HLA-B $* 5201$ positives than in the HLA-B*5201 negatives.

The clinical characteristics between the HLA-DPB1*0202 positive and negative groups were also compared, as shown in table 6. The incidence of deep vein thrombosis in the HLADPB1*0202 positives was marginally lower than that in the HLA-DPB1 ${ }^{* 0202}$ negatives $(p=0.06)$. However, the cardiac index was significantly lower in the HLA-DPB1*0202 positives than in the HLA-DPB ${ }^{*} 0202$ negatives, while the total pulmonary vascular resistance was slightly higher in the HLA-DPB1*0202 positives with marginal significance $(\mathrm{p}=0.05) . \quad \mathrm{Pa}_{2} \mathrm{O}_{2}, P \mathrm{~Pa}_{1} \mathrm{O}_{2}$, and $\mathrm{P}_{\mathrm{v}, \mathrm{O}_{2}}$ in the HLA-DPB1*0202 positives were significantly impaired as compared with those in the HLA-DPB1*0202 negatives.

In addition, the incidence of deep vein thrombosis in the patients carrying HLA-B*5201 and/or HLA-DPB1*0202 was significantly
TABLE 6 Comparison of clinical characteristics between the HLA-DPB1*0202 positive and negative patients

\begin{tabular}{|c|c|c|}
\hline & $\begin{array}{l}\text { DPB1*0202 } \\
\text { positives }\end{array}$ & $\begin{array}{l}\text { DPB } 1 * 0202 \\
\text { negatives }\end{array}$ \\
\hline Subjects $n$ & 15 & 65 \\
\hline Female versus male & $2: 1$ & $3.6: 1$ \\
\hline $\begin{array}{l}\text { Central versus peripheral Predom } \\
\text { inant types }\end{array}$ & $2.8: 1$ & $1.7: 1$ \\
\hline Deep vein thrombosis \% & 6.3 & 30.8 \\
\hline Duration of symptoms months & $39.3 \pm 38.2$ & $25.8 \pm 26.7$ \\
\hline Mean Ppa mmHg & $45.9 \pm 10.3$ & $42.2 \pm 10.3$ \\
\hline Cardiac index $L \cdot \min ^{-1} \cdot \mathrm{m}^{-2}$ & $2.37 \pm 0.37^{*}$ & $2.71 \pm 0.55^{*}$ \\
\hline $\begin{array}{l}\text { Total pulmonary vascular } \\
\text { resistance dynes } \cdot \mathbf{s} \cdot \mathrm{cm}^{-5}\end{array}$ & $1009 \pm 299$ & $845 \pm 297$ \\
\hline $\mathrm{Pa}, \mathrm{O}_{2} \mathrm{kPa}$ & $7.4 \pm 1.0^{*}$ & $8.2 \pm 1.4$ \\
\hline $\mathrm{PAa}, \mathrm{O}_{2} \mathrm{KPa}$ & $6.7 \pm 1.0^{*}$ & $5.9 \pm 1.6^{*}$ \\
\hline${\mathrm{Pv}, \mathrm{O}_{2}}_{\mathrm{kPa}}$ & $4.1 \pm 0.4^{\star \star}$ & $4.6 \pm 0.8^{* *}$ \\
\hline $\begin{array}{l}\text { Fletcher-Hugh-Jones } \\
\text { classification }\end{array}$ & $3.1 \pm 0.8$ & $3.0 \pm 0.9$ \\
\hline
\end{tabular}

Values are presented as mean \pm SD unless otherwise stated. Duration of symptoms: duration from symptoms onset to cardiac catheterisation. Ppa: pulmonary arterial pressure; $\mathrm{Pa}_{1} \mathrm{O}_{2}$ : arterial oxygen tension; $P_{A a}, \mathrm{O}_{2}$ : alveolararterial oxygen tension difference; $P_{\mathrm{v}, \mathrm{O}_{2}}$ : mixed venous oxygen tension. * $p<0.05 ;{ }^{* *}: p<0.01$, Mann-Whitney U-test and Chi-squared test.

lower than that in the patients carrying neither of the diseaseassociated HLA alleles (16.2 versus $40.5 \%$, $\mathrm{p}=0.007$ ).

\section{DISCUSSION}

The incidence of pulmonary thromboembolism in Japan $(3,492$ patients per year) was much lower than in the USA $(630,000$ per year) [24]. The absence of factor V Leiden and prothrombin mutations, and low lipid level in the Japanese might be involved in the difference between Japanese and Caucasian populations [24, 25]. Female predominance and a higher incidence ratio of chronic to acute pulmonary thromboembolism in Japan as compared with those in the USA were recently reported [3]. In addition, the incidence of deep vein thrombosis in CTEPH is only $12-38 \%$ in Japan [3-5], compared with 35$45 \%$ in the USA [2]. These observations prompted the current authors to search for a possible genetic factor related to the difference in disease incidence and phenotype of CTEPH between the USA and Japan. This is the first report to show a strong association between CTEPH and HLA alleles at the DNA level. Higher frequencies of HLA-B*5201 and HLA-DPB1*0202 were found in the patients. HLA-B*5201 and HLA-DPB1* 0202 were independently associated with CTEPH. HLA-B* 5201 positive patients showed significant female predominance and had mild disease phenotypes, whereas HLA-DPB1*0202-positive patients showed severe clinical parameters. The incidence of deep vein thrombosis was low in the patients carrying HLA-B*5201 and/or HLA-DPB1*0202.

RIEDEL et al. [26] disclosed the association of HLA-Cw4 and -Bw35 with venous thromboembolism in Caucasian Czechs. They also reported that recurrent emboli, positive family 
history of venous thromboembolism, and severe CTEPH (mean $P$ pa $>40 \mathrm{mmHg}$ ) were related to HLA-Cw4. However, there was no association of HLA-B35 with CTEPH. In the current preliminary study by serological method, there was no association of HLA-Cw4 with CTEPH $(n=50)(15.0$ versus $9.0 \%$, OR 1.67, $p=0.24$ ) regardless of the history of deep vein thrombosis. In addition, this preliminary study did not show any significant association of either HLA-B $* 5201$ (10 versus $24 \%$, OR $0.36, \mathrm{p}=0.08$ ) or $-\mathrm{DPB} 1 * 0202$ (7 versus $6 \%$, OR 1.05 , $\mathrm{p}=0.94$ ) allele with acute pulmonary thromboembolism originating from deep vein thrombosis in 30 patients. A genetic basis underlying the propensity to develop CTEPH after an episode of acute pulmonary embolism may exist and will be defined in the future.

The relationships between HLA-DR, -DQ loci and pulmonary arterial hypertension have been investigated [9, 11-13]. There was an increased frequency of HLA-DR3, -DR52, -DQ2 in children with primary pulmonary hypertension (PPH) [11], and PPH in HIV infection was associated with HLA-DR6 and HLA-DR52 [12]. MORSE et al. [13] reported that antibodies to fibrin-bound tissue plasminogen activator and HLA-DQ7, and possibly the same epitope associated with lupus anticoagulant, defined a small subset of children and adults with PPH. The presence of HLA-DR6 and -DR52 was associated with significantly increased risk of fatal disease outcome with pulmonary hypertension in scleroderma [9]. However, in the current study the association of CTEPH and HLA-DRB1*1502 was caused by linkage disequilibrium with HLA-B*5201 [19, 20] and was not expected to be primary because the OR of DRB1*1502 (0.90) in the HLA-B*5201-negative group was $<1$, and the OR of HLA-B*5201 (2.50) in the HLA-DRB1*1502positive group was greater than that of the HLA-DRB1*1502 (1.77) in the HLA-B*5201-positive group.

No patients with autoimmune disease-related pulmonary arterial hypertension, except antiphopholipid syndrome, were included.

It has been suggested that lupus anticoagulant and/or antiphospholipid antibodies, were associated with CTEPH $[22,23]$, and antiphospholipid syndrome has been immunogenetically correlated with some alleles of HLA class II loci, including HLA-DR4, -DR7, -DRw53 and -DQB1*0302 [27]. In a Japanese series, a possible association of DRB1*0901 with systemic lupus erythematosus patients with $\beta_{2}$ glycoprotein I was found [28]. In the current series 12 patients (15\%) had lupus anticoagulant and/or antiphospholipid antibodies, but there was no significant association with HLA-B*5201 or -DPB1*0202.

MORSE and BARST [29] speculated that the induction of activation molecules, such as HLA class II, on endothelial cells with inflammatory infiltrates, and the release of cytokines and mediators, as well as the initiation of noninflammatory vasculopathy via recurrent thromboembolism or thrombosis in situ, or both, might be related to the pathogenesis of pulmonary arterial hypertension. A previous study by the authors showed that the circulating levels of monocyte chemoattractant protein-1, tumour necrosis factor alpha (TNF- $\alpha$ ), and interleukin-1 $\beta$ were high in CTEPH [20]. Several heterogeneous immunologic events might also play a role in the development of CTEPH.
A recent study showed elevated plasma factor VIII levels in CTEPH [30]. The current authors measured factor VIII plasma levels in 27 of 80 patients, and their prevalence at $>150 \mathrm{IU} \cdot \mathrm{dL}^{-1}$ was $74.1 \%$. There was no association of factor VIII plasma levels of $>150 \mathrm{IU} \cdot \mathrm{dL}^{-1}$ with either HLA-B*5201 or -DPB1*0202. A high prevalence of non-O blood groups in CTEPH has been shown in western countries [31]. Non-O blood groups were also found to be more prevalent in CTEPH patients $(83.5 \%$, $\mathrm{n}=79, \mathrm{p}<0.0001)$ than in patients with pulmonary arterial hypertension $(58.3 \%, n=60)$, or in the Japanese population $(\sim 69 \%)$. There was no association of non-O blood groups with either HLA-B*5201or -DPB1*0202.

The association of Behcet's disease and HLA-B51 has been reported [10], and Behcet's patients had an increased risk of venous thrombosis [32]. None of the patients in the current study had Behcet's disease.

The mechanism of the associations of HLA-B*5201 and -DPB1*0202 with CTEPH remains unknown. HiRsCH et al. [33] reported unilateral pulmonary artery thrombotic occlusion type (female-to-male ratio; 10:1) showing poor restoration of perfusion and a high frequency of rethrombosis post-operatively. They speculated that post-obstructive pulmonary arteriopathy might be related to poor outcome. In the current series, only five patients showed unilateral thrombotic occlusion. However, it is known that Takayasu arteritis is more prevalent in Asia and South America than elsewhere [34, 35]. This disease is also epidemiologically known for its female predominance and the association of HLA-B*5201 with Takayasu arteritis has been well documented in Japan [18, $19,21,34-37]$. Takayasu arteritis is a chronic vasculitis, mainly involving the aorta and its major branches, as well as the coronary and pulmonary arteries [35, 38]. The frequency of HLA-B $5201(40 \%)$ in CTEPH was similar to that reported in Takayasu arteritis (41.3\%) [21].

KERR et al. [39] reported four cases of large vessel arteritis mimicking CTEPH. All had systemic arterial involvement. Two were operated on, with dense adhesion and occluded pulmonary artery with white fibrous material being observed in one, and aneurysm in the right pulmonary artery and endarterectomised organised thrombi in the left pulmonary artery in the other. The current authors excluded Takayasu arteritis using computed tomography angiographies and $\mathrm{C}$ reactive protein (CRP). No patients showed the symptoms or findings of systemic arterial involvement.

LIE [40] reported cases of isolated pulmonary Takayasu arteritis without systemic involvement. The current authors excluded patients showing only high attenuation wall thickening similar to Takayasu arteritis [41]. CRP was $\geqslant 0.3 \mathrm{mg} \cdot \mathrm{dL}^{-1}$ in six of 80 patients, and three had complications (one atypical mycobacterium, one Hashimoto disease, and one haemolytic anaemia). One patient had undergone surgery and Takayasu arteritis was excluded, and the remaining two underwent aortography, but no evidence of Takayasu arteritis was observed. However, there is still a possibility that these two diseases overlap in the Japanese patient population and may, in medically treated cases, be indistinguishable, as the pathological findings of isolated pulmonary Takayasu arteritis include organised thrombi in segmental or distal arteries [40]. 
The current authors could not observe stenosis due to adventitial lesions suggestive of Takayasu arteritis, but noted thickened wall and organised thrombi suggestive of CTEPH in 39 patients who underwent pulmonary thromboendarterectomy. Although the patients with HLA*B5201 positive type had more proximal thrombi and slightly mild pulmonary haemodynamics compared with HLA*B5201 negative type, the postoperative pulmonary vascular resistance and the reduction rate in total pulmonary vascular resistance by surgery did not show any significance between them $(p>0.87)$. Because preoperative location of thrombi and pulmonary vascular resistance are major determinants of surgical outcome [42], further large studies are needed to confirm the difference of surgical outcome between them.

However, the current authors observed growth of thrombi to the proximal side in the pulmonary artery in three patients, all being HLA-B*5201 positive, but CRP was $<0.3 \mathrm{mg} \cdot \mathrm{dL}^{-1}$. An autopsy case showed diffuse inflammatory cell infiltrates in the media, accompanied by disruption of elastic fibre and granulation in the media in large elastic pulmonary arteries to which thrombi were attached. Those findings mimicked, but were different from Takayasu arteritis based on the fact that adventitial lesions were not observed. It is possible that more cases of underdiagnosed pulmonary arteritis secondary to thrombi were included in CTEPH carrying HLA-B*5201. Further studies including the measurement of high sensitivity CRP are needed to confirm the association of subclinical inflammation and CTEPH.

There are two possibilities concerning the roles of HLA in controlling the susceptibility to CTEPH. One is that the diseaseassociated HLA alleles are in linkage disequilibrium with unknown gene(s) that are actually involved in the pathogenesis of the disease. The other is that the HLA molecule itself may play an important role in the pathogenesis. A recent study using microsatellite markers in the HLA region has revealed that there are two susceptibility genes for Takayasu arteritis; one locates between the TNF- $\alpha$ gene and MICB gene, while the other is HLA$B * 5201$ itself [37]. Future microsatellite studies around the HLA class I region may reveal either similarity or difference between Takayasu arteritis and CTEPH, and may decipher the HLAlinked susceptibility gene(s) to CTEPH.

THISTLETHWAITE et al. [43] reported that operative classification (types 1-4) of CTEPH determines outcome after pulmonary thromboendarterectomy. The patients in the current study with central predominant type were classified as type 1 or 2 , and peripheral predominant type was classified as type 3 except for two patients in the surgical group $(n=39)$. The current authors used their stratification, as precise application of the operative classification to the patients in the medical group was not feasible.

Several differences in the clinical characteristics in association with the HLA alleles were found in the current study. Because of the wide spectrum of clinical characteristics in CTEPH, there might be at least three types of the disease. The first is predominant to female and is a mild type associated with HLA-B*5201. Female predominance in Japanese CTEPH could be partly explained by the HLA-B*5201-related type. The second is a severe type associated with HLA-DPB1*0202. These two types were less related with deep vein thrombosis, and they showed a tendency to contain more of the central predominant type. The third, as found in the USA, is in relation to deep vein thrombosis. This type may not be associated with any HLA alleles, as shown in this study.

The current authors do not know exactly why patients with HLA-B*5201 showed mild haemodynamics. Perhaps this is related to the shorter duration of symptoms because there was no episode of deep vein thrombosis and the fact that there were central predominant thrombi without peripheral involvement.

Only the association of HLA-DPB $1 * 0202$ and type 1 diabetes was reported [44, 45], but this association was not found in Japanese series. It remains unknown why the patients with HLA-DPB1*0202 had severe disease.

\section{Study limitations}

There are several issues regarding limitations to the study. First, sex-age matched control were not used. In the series both patients and controls were Japanese residing on the main islands of Honshu and Kyushu. It is well known that the frequencies of HLA alleles are not significantly different among populations residing on each main island. For example, the prevalence of HLA-B ${ }^{*} 5201$ in the control was $23.7 \%$ $(n=678)$, similar to or slightly higher than the reported prevalence of $20.2 \%(n=371)$ [46], and 20.6\% $(n=523)$ [47], both on Honshu island. Similarly, the prevalence of DPB1*0202 in the control was $6.3 \%$, comparable to the reported prevalence of $6.7 \%$ and $7.0 \%$ from the same Honshu island studies. This suggests that the control group in the current study is a reasonable sample of the source population with regard to those loci in Japan. Japanese on the main islands are well known to be genetically homogeneous, and genotype frequencies of HLA alleles were thought to be within the HardyWeinberg equilibrium [48] in both patients and controls. Although unlikely, it might still be difficult to completely rule out the possibility that the CTEPH patient group could have originated from a subpopulation that could cause false positive associations due to population stratification.

Secondly, the number of patients in each subcategory was small in the current series. Larger studies are needed to confirm the differences of the clinical characteristics in association with the HLA alleles.

Thirdly, the finding of a female prevalence (3.1:1) is very unusual compared with CTEPH in the western world. Caucasian populations were not analysed for HLA to confirm a distinct disease pattern of CTEPH in Japan. The incidence of HLA-B*5201 and -DPB1*0202 is low in Caucasians [7], as is the prevalence of CTEPH without deep vein thrombosis. Thus, this unique HLA associated CTEPH might be limited to the Japanese.

In conclusion, female predominant chronic thromboembolic pulmonary hypertension without deep vein thrombosis does exist in Japan, and the disease was associated with HLA-B*5201 and HLA-DPB1*0202. The susceptibility and/or clinical phenotypes of chronic thromboembolic pulmonary hypertension may be controlled in part by genes in the HLA-B and -DPB1 loci. 


\section{ACKNOWLEDGEMENTS}

The authors thank W.W. Wagner, Jr. for helpful criticism to the manuscript, and S. Kominami for HLA typing of acute pulmonary thromboembolism. This study was supported in part by a research grant for the Research Committee, Intractable Respiratory Failure, a research grant for Cardiovascular Diseases (14-5) from the Ministry of Health, Labor and Welfare of Japan, a Grant-in-Aid from the Ministry of Education, Science, Sports, Culture and Technology of Japan, and a grant from the Japan Cardiovascular Research Foundation.

\section{REFERENCES}

1 Moser KM, Auger WR, Fedullo PF. Chronic major-vessel thromboembolic pulmonary hypertension. Circulation 1990; 81: 1735-1743.

2 Fedullo PF, Auger WR, Kerr KM, Rubin LJ. Chronic thromboembolic pulmonary hypertension. N Engl J Med 2001; 345: 1465-1472.

3 Nakamura M, Okada O, Sakuma M, et al. Incidence and clinical characteristics of chronic pulmonary thromboembolism in Japan compared to acute pulmonary embolism results of multicenter registry of the Japanese society of pulmonary embolism research. Circ J 2002; 66: 257-260.

4 Tanabe N, Okada O, Nakagawa Y, et al. The efficacy of pulmonary thromboendarterectomy on long-term gas exchange. Eur Respir J 1997; 10: 2066-2072.

5 Kunieda T, Naito M, Ookubo S, Yoshioka K, Nakanishi N, Oobayashi Y. Clinical aspects and diagnosis of pulmonary thromboembolism. Jpn J Thorac Dis 1988; 26: 463-472.

6 Archibald CJ, Auger WR, Fedullo PF, et al. Long-term outcome after pulmonary thromboendarterectomy. Am J Respir Crit Care Med 1999; 160: 523-528.

7 Imanishi T, Akazawa T, Kimura A, Tokunaga K, Gojobori T. Allele and haplotype frequencies for HLA and complement loci in various ethnic groups. In: Tsuji K, Aizawa M, Sasazuki T, eds. HLA 1991, vol 1. New York, Oxford University Press, 1992; pp. 1065-1220.

8 Kitamura H, Kobayashi Y, Kimura A, Numano F. Association of clinical manifestations with HLA-B alleles in Takayasu arteritis. Int J Cardiol 1998; 66: Suppl. 1, s121-s126.

9 Langevitz BYP, Buskila D, Gladman DD, Darlington GA, Farewell VT, Lee P. HLA alleles in systemic sclerosis: association with pulmonary hypertension. $\mathrm{Br} J$ Rheumatol 1992; 31: 609-613.

10 Mizuki N, Ota M, Katsuyama Y, et al. Association analysis between the MIC-A and HLA-B: alleles in Japanese patients with Behcet's disease. Arthritis Rheum 1999; 42: 1961-1966.

11 Barst RJ, Flaster ER, Menon A, Fotino M, Morse JH. Evidence for the association of unexplained pulmonary hypertension in children with the major histocompatibility complex. Circulation 1992; 85: 249-258.

12 Morse JH, Barst RJ, Itescu S, et al. Primary pulmonary hypertension in HIV infection: an outcome determined by particular HLA class II alleles. Am J Respir Crit Care Med 1996; 153: 1299-1301.

13 Morse JH, Barst RJ, Fotino M, et al. Primary pulmonary hypertension, tissue plasminogen activator antibodies, and HLA-DQ7. Am J Respir Crit Care Med 1997; 155 274-278.

14 Tanabe N, Okada O, Abe Y, Masuda M, Nakajima N, Kuriyama T. The influence of fractional pulse pressure on the outcome of pulmonary thromboendarterectomy. Eur Respir J 2001; 17: 653-659.

15 Auger WR, Fedullo PF, Moser KM, Buchbinder M, Peterson KL. Chronic major-vessel thromboembolic pulmonary artery obstruction: appearance at angiography. Radiology 1992; 182: 393-398.

16 Hugh-Jones P. A simple standard exercise test and its use for measuring exertion dyspnoea. BMJ 1952; 1: 65-71.

17 Terasaki PI. Microdroplet lymphocytotoxicity test. In: Ray JG, Hare DB, Pedersen PD, eds. Manual of tissue typing techniques. Bethesda, DHEW publications NO. (NIH) 76545, 1976; pp. 69-80.

18 Yoshida M, Kimura A, Katsuragi K, Numano F, Sasazuki T. DNA typing of HLA-B gene in Takayasu's arteritis. Tissue Antigens 1993; 42: 87-90.

19 Dong RP, Kimura A, Numano F, Nishimura Y, Sasazuki T. HLA linked susceptibility and resistance to Takayasu arteritis. Heart Vessels 1992; 7: 73-80.

20 Kimura H, Okada O, Tanabe N, et al. Plasma MCP-1 and pulmonary vascular resistance in chronic thromboembolic pulmonary hypertension. Am J Respir Crit Care Med 2001; 164: 319-324.

21 Kimura A, Kitamura H, Date Y, Numano F. Comprehensive analysis of HLA genes in Takayasu arteritis in Japan. Int J Cardiol 1996; 54: Suppl. s61-s69.

22 Auger WR, Permpikul P, Moser KM. Lupus anticoagulant, heparin use and thrombocytopenia in patients with chronic thromboembolic pulmonary hypertension: A preliminary report. Am J Med 1995; 99: 392.

23 Wolf M, Boyer-Neumann C, Parent F, et al. Thrombotic risk factors in pulmonary hypertension. Eur Repir J 2000; 15 : 395-399.

24 Kumasaka N, Sakuma M, Shirato K. Incidence of pulmonary thromboembolism in Japan. Jpn Circ J 1999; 63: 439-441.

25 Murata M. Genetic polymorphisms associated with thrombotic disorders in the Japanese population. Fibrinolysis and Proteolysis 2000; 14: 155-164.

26 Riedel M, Ivaskova E, Sajdlova H. HLA and venous thromboembolism. Tissue Antigens 1981; 18: 280-281.

27 Sebastiani GD, Minisola G, Galeazzi M. HLA class II alleles and genetic predisposition to the antiphospholipid syndrome. Autoimmunity Reviews 2003; 2: 387-394.

28 Hashimoto H, Yamanaka K, Tokano Y, et al. HLA-DRB1 alleles and beta 2 glycoprotein I-dependent anticardiolipin antibodies in Japanese patients with systemic lupus erythematosus. Clin Ex Rheumatol 1998; 16: 423-427.

29 Morse JH, Barst RJ. Immunologic disturbances in primary pulmonary hypertension. Semin Respir Crit Care Med 1994; 15: 222-229.

30 Bonderman D, Turecek PL, Jakowitsch J, et al. High prevalence of elevated clotting factor VIII in chronic thromboembolic pulmonary hypertension. Thromb Haemost 2003; 90: 372.

31 Lang IM, Bonderman D, Jakowitsch J, Skoro-Sajer N, Klepetko W, Kneussl M. Chronic thromboembolic pulmonary hypertension: update 2004. In: Demedts M, Delcroix M, Verhaeghe R, Verleden GM, eds. Pulmonary 
vascular pathology: A clinical update. Eur Respir Mon 2004: 27; 243-252.

32 Ames PR, Steuer A, Pap A, Denman AM. Thrombosis in Behcet's disease: a retrospective survey from a single UK center. Rheumatology 2001; 40: 652-655.

33 Hirsch AM, Moser KM, Auger WR, Channick RN, Fedullo PF. Unilateral pulmonary artery thrombotic occlusion: Is distal arteriopathy a consequence? Am J Respir Crit Care Med 1996; 154: 491-496.

34 Ishikawa K. Natural history and classification of occlusive thromboaortopathy. Circulation 1978; 58: 173-177.

35 Numano F. Hereditary factors of Takayasu arteritis. Heart Vessels 1992; Suppl. 7, 68-72.

36 Numano F, Isohisa I, Maezawa H, Juli H. HLA antigens in Takayasu arteritis. Am Heart J 1979; 98: 153-159.

37 Kimura A, Ota M, Katsuyama Y, et al. Mapping of the HLA-linked genes controlling the susceptibility to Takayasu's arteritis. Int J Cardiol 2000; 75: Suppl. 75, S105-S110.

38 Lupi HE, Sanchez TG, Horwitz S, Gutierrez FE. Pulmonary artery involvement in Takayasu's arteritis. Chest 1975; 67: 69-74.

39 Kerr KM, Auger WR, Fedullo PF, Channick RH, Yi ES, Moser KM. Large vessel arteritis mimicking chronic thromboembolic disease. Am J Respir Crit Care Med 1995; 152: 367-373.

40 Lie JT. Isolated pulmonary Takayasu arteritis: clinicopathologic characteristics. Mod Pathol 1996; 9: 469-474.
41 Roberts HC, Kauczor H-U, Schweden F, Thelen M. Spiral CT of pulmonary hypertension and chronic thromboembolism. J Thorac Imaging 1997; 12: 118-127.

42 Bergin CJ, Sirlin C, Deutsch R, et al. Predictors of patient response to pulmonary thromboendarterectomy. Am J Roentgenol 2000; 174: 509-515.

43 Thistlethwaite PA, Mo M, Madani MM, et al. Operative classification of thromboembolic disease determines outcome after pulmonary endarterectomy. J Thoracic Cardiovasc Surg 2002; 124: 1203-1211.

44 Valdes AM, Noble JA, Genin E, Clerget-Darpoux F, Erlich HA, Thomson G. Modeling of HLA class II susceptibility to type 1 diabetes reveals an effect associated with DPB1. Genetic Epidemiology 2001; 21: 212-223.

45 Bugawan TL, Kliltz W, Alejandrino M, et al. The association of specific HLA class I and II alleles with type 1 diabetes among Filipinos. Tissue Antigens 2002; 59: 452-469.

46 Saito S, Ota S, Yamada E, Inoko H, Ota M. Allele frequencies and haplotypic associations defined by allelic DNA typing a HLA class I and II loci in the Japanese population. Tissue Antigens 2000; 56: 522-529.

47 Nakajima F, Nakamura J, Yokota T. Analysis of HLA haplotypes in Japanese, using high resolution allele typing. MHC 2001; 8: 1-32.

48 Sofer JA. Population genetics (Hardy-Weinberg equilibrium and factors affecting it). In: Emery AE, Rimoin DL, eds. Principles and practice of medical vol 1. Edinburgh, Churchill Livingstone 1990; pp. 121-132. 